\title{
The COVID-19 Pandemic Mental Health Questionnaire (CoPaQ): psychometric evaluation and compliance with countermeasures in psychiatric inpatients and non-clinical individuals
}

Stephanie V. Rek ${ }^{1,2^{*}}$, Markus Bühner ${ }^{3}$, Matthias A. Reinhard ${ }^{1}$, Daniel Freeman ${ }^{4}$, Daniel Keeser ${ }^{1}$, Kristina Adorjan ${ }^{1}$, Peter Falkai ${ }^{1}$ and Frank Padberg ${ }^{1}$

\begin{abstract}
Background: The COVID-19 pandemic has greatly impacted people's lives across a broad spectrum of psychosocial domains. We report the development and psychometric evaluation of the self-report COVID-19 Pandemic Mental Health Questionnaire (CoPaQ), which assesses COVID-19 contamination anxiety, countermeasure necessity and compliance, mental health impact, stressor impact, social media usage, interpersonal conflicts, paranoid ideations, institutional \& political trust, conspiracy beliefs, and social cohesion. Further, we illustrate the questionnaire's utility in an applied example investigating if higher SARS-Cov-2 infection rates in psychiatric patients could be explained by reduced compliance with preventive countermeasures.
\end{abstract}

Methods: A group of 511 non-clinical individuals completed an initial pool of 111 CoPaQ items (Open Science Framework: https://osf.io/3evn9/) and additional scales measuring psychological distress, well-being, and paranoia to assess construct validity and lifetime mental health diagnosis for criterion validity. Factor structure was determined by exploratory factor analyses and validated by conducting confirmatory factor analysis in the accompanying longitudinal sample $(n=318)$ and an independent psychiatric inpatient sample primarily admitted for major depressive-, substance abuse-, personality-, and anxiety disorders $(n=113)$. Internal consistency was assessed by Cronbach's Alpha and McDonald's Omega. For the applied research example, Welch t-tests and correlational analyses were conducted.

Results: Twelve out of 16 extracted subscales were retained in the final questionnaire version, which provided preliminary evidence for adequate psychometric properties in terms of factor structure, internal consistency, and construct and criterion validity. Our applied research example showed that patients exhibited greater support for COVID-19 countermeasures than non-clinical individuals. However, this requires replication in future studies.

\footnotetext{
* Correspondence: s.rek@med.uni-muenchen.de

'Department of Psychiatry and Psychotherapy, LMU University Hospital Munich, Nussbaumstraße 7, Munich, Germany

${ }^{2}$ International Max Planck Research School for Translational Psychiatry (IMPRS-TP), Munich, Germany

Full list of author information is available at the end of the article
}

(C) The Author(s). 2021 Open Access This article is licensed under a Creative Commons Attribution 4.0 International License, which permits use, sharing, adaptation, distribution and reproduction in any medium or format, as long as you give appropriate credit to the original author(s) and the source, provide a link to the Creative Commons licence, and indicate if changes were made. The images or other third party material in this article are included in the article's Creative Commons licence, unless indicated otherwise in a credit line to the material. If material is not included in the article's Creative Commons licence and your intended use is not permitted by statutory regulation or exceeds the permitted use, you will need to obtain permission directly from the copyright holder. To view a copy of this licence, visit http://creativecommons.org/licenses/by/4.0/ The Creative Commons Public Domain Dedication waiver (http://creativecommons.org/publicdomain/zero/1.0/) applies to the data made available in this article, unless otherwise stated in a credit line to the data. 
Conclusions: We demonstrate that the CoPaQ is a comprehensive and valid measure of the psychosocial impact of the pandemic and could allow to a degree to disentangle the complex psychosocial phenomena of the pandemic as exemplified by our applied analyses.

Keywords: Coronavirus, Psychosocial impact, Questionnaire validation, Factor analysis, Preventive countermeasures

\section{Introduction}

The COVID-19 pandemic and related governmental restrictions and recommendations to contain the rapid spread of the coronavirus (e.g., stay-at-home orders \& social distancing) have greatly changed people's lives. Early on, news outlets and initial research have cautioned that the COVID-19 pandemic would affect and be affected by a number of key aspects of individuals' lives. These aspects include mental health and pandemic-related stress, risk and protective factors (contamination anxiety, social media usage, interpersonal conflicts, mental health-protective behaviour), and individuals' perception of the political handling of the crisis (conspiracy beliefs, political and institutional trust, and support of public health directives; e.g. [1-3],). We developed the COVID-19 Pandemic Mental Health Questionnaire $(\mathrm{CoPaQ})$ in order to capture this wide pandemic-related psychosocial spectrum applicable for different study populations. The self-report questionnaire was published on the Open Science Framework (OSF; https://osf.io/3evn9/) in German and English early on in the pandemic in April, 2020 [4]. Since then, the instrument has received recognition from the wider research community worldwide with translations into Spanish, Croatian, Portuguese, Greek, Hungarian, Korean, Nepalese, Czech, and Romanian illustrating that the questionnaire has been well received and was applied frequently in different countries and study populations. To date, however, a psychometric validation of the $\mathrm{CoPaQ}$ has been lacking.

The present study aims to provide a comprehensive description and psychometric evaluation of the $\mathrm{CoPaQ}$. We recruited a group of non-clinical individuals online $(n=511)$ and psychiatric inpatients from the LMU Biobank study $(n=113)$. They completed the CoPaQ and validated self-report measures on psychological distress, wellbeing, and paranoia. To determine the factor structure, selection of items, and model fit, we applied exploratory factor analyses (EFA) in our non-clinical derivation sample. We then evaluated this factor structure by applying confirmatory factor analyses (CFA) using accompanying longitudinal 10-week follow-up data $(n=318)$ and separate CFA for the psychiatric inpatient sample. Internal consistency was determined using McDonald's Omega and Cronbach's Alpha across samples. For selected subscales of the $\mathrm{CoPaQ}$, we evaluated criterion- and construct validity.

In addition to the psychometric validation of the $\mathrm{CoPaQ}$, we illustrate the questionnaire's utility in an applied research example. Previously, two large US cohort studies have suggested that patients with a history of mental disorders have an increased risk for SARSCov-2 infection even when controlling for important socioeconomic and health-related factors $[5,6]$. The authors suggest that one explanation for the increased risk of SARS-Cov-2 infection could be patients' lower compliance with public health directives (hygiene measures, social distancing guidelines, and political restrictions). However, this hypothesis and potential explanatory factors have not been investigated empirically.

A number of factors have been associated with individual differences in levels of compliance in the public with governmental guidelines. Higher levels of an individual's risk perception [7-9] as well as political and institutional trust [10] have been found to increase support for governmental regulations. Contrary to this, erroneous conspiracy beliefs about the origin of the coronavirus have been associated with reduced adherence to preventive measures [2]. Consequently, multiple plausible and partly diverging hypotheses could explain potential differences in support of governmental restrictions and regulations between psychiatric patients and non-clinical individuals. First, lower levels of trust may promote less adherent behaviours in psychiatric patients, which may be reflected in lower levels of COVID-19 institutional \& political trust and higher levels of COVID-19 conspiracy beliefs and paranoid ideations, compared to non-clinical individuals. Conversely, psychiatric patients' adherence to COVID-19 countermeasures could be greater than in non-clinical controls as patients may exhibit higher levels of COVID-19 contamination anxiety, more COVID-19 physical risk factors, and overall greater general anxiety symptoms. These fear-related characteristics could promote protective behaviours against SARS-Cov-2 infection as reflected in higher levels of COVID-19 contamination anxiety, COVID-19 physical risk factors and general anxiety symptoms, compared to non-clinical individuals. Here, psychiatric patient populations may differ in their levels of mistrust, which is most characteristic for psychotic disorders and fear, which is most characteristic for anxiety disorders. In this study, we focused on a transdiagnostic psychiatric inpatient sample from all major diagnostic categories with most prominent prevalence of major depressive-, substance abuse-, personality-, and anxiety disorders. Testing these hypotheses requires the assessment of a number of COVID-19 related psychosocial 
domains, which provides the ideal setting to explore the utility of the $\mathrm{CoPaQ}$ questionnaire in the context of our case-control sample.

\section{Study Part 1: Questionnaire validation}

\section{Methods}

\section{$\mathrm{CoPaQ}$ construction}

The initial item pool was devised by the study team (psychiatrist and clinical psychologists) based upon clinical experience, reference to the current diagnostic classification system of Diagnostic And Statistical Manual Of Mental Disorders, fifth edition [11], reference to existing measures [12], and an extensive internet search for current media and research outputs [13-16]. Thereafter, each item was evaluated with regard to its face and content validity by independent experts (two examinees). A final construct of questions was designed, ensuring no overlap. Due attention was given to ensure that the questions were framed in simple language, and worded positively, with no ambiguity.

The first part of the questionnaire served to characterise the population under study by asking about SARS-Cov-2 infection status, COVID-19 physical health risk factors (self/others), employment status, health insurance status, life time mental health diagnosis, etc. The subsequent item pool was devised to reflect the following COVID-19related constructs: contamination anxiety ( 9 items), necessity of and compliance with countermeasures (29 items), mental health symptomatology (25 items), positive coping (12 items), stressors (29 items), interpersonal conflicts (5 items), social media usage (7 items), political and institutional trust (6 items), paranoid ideations (5 items), conspiracy beliefs (7 items), and social cohesion (6 items). The time period for all the items was either relating to the present moment or the previous 2 weeks. Items were rated on a 0 (not at all) to 4 (very much) scale.

We disseminated the questionnaire to the wider research community prior to validation to facilitate its use during the rapidly unfolding events during the pandemic.

\section{Participants}

To extract the items for the new measures of the psychosocial impact of the COVID-19 pandemic, a derivation sample of 511 participants from the general German population completed the full item pool (mean age $=30.12, \quad \mathrm{SD}=11.15$, female $=400$, male $=110$, diverse $=1$ ). The derivation sample is part of an ongoing longitudinal survey into the mental health consequences of the pandemic. The subset of individuals who provided data for a second time $(n=318)$ formed our longitudinal validation sample (mean age $=30.54, \mathrm{SD}=11.28$, female $=249$, male $=68$, diverse $=1$ ). There were no significant differences between derivation sample and longitudinal validation sample in terms of age, sex, marital status, ethnicity, or employment status $(p>.05)$. A second cross-validation sample consisted of 113 psychiatric inpatients (mean age $=43.93, \mathrm{SD}=14.64$, female $=$ 55 , male $=58$ ) recruited from the LMU Biobank study.

\section{Procedure}

Non-clinical participants were recruited online via social media advertisements (Facebook) and university mailing lists to participate in the survey including the $\mathrm{CoPaQ}$ and other questionnaires (see below). The survey was run using the secure online LimeSurvey software. A forced response format was applied and only complete responses were included in the current analyses $(n=592)$. We excluded participants who gave incorrect responses to more than one out of three included bogus items (e.g., "Please, indicate completely agree"; $n=47$ ) and with response times $<25 \mathrm{~min}$, which we considered highly unlikely (median completion duration $=48 \mathrm{~min}$; interquartile range $[\mathrm{IQR}]=38-60 ; n=7)$. At the end, by entering their email addresses participants had the opportunity to be included in a prize draw and take part in the 10-week follow-up assessment. Those participants at the 10-week follow-up time point who had response times $<15 \mathrm{~min}$, which we considered highly unlikely (median completion duration = 29 min, IQR $=23-39.5 ; n=7$ ), were additionally excluded.

Psychiatric inpatients were recruited as part of the LMU Biobank study from the Department of Psychiatry and Psychotherapy of the LMU University Hospital Munich. Participants filled out the $\mathrm{CoPaQ}$ and other questionnaires (see below) using paper-pencil $(n=144)$. Exclusion criteria comprised an insufficient comprehension of German, an acute psychotic or manic episode, or acute suicidality. Furthermore, psychiatric inpatients' responses were excluded if they had more than $10 \%$ missing data on each of the self-report questionnaires $(n=$ 31). Missing values were then imputed using the missForest package [17] for non-parametric, iterative random-forest based imputation, which resulted in an imputation error of Out-of-bag PFC $=0.1748$.

To ensure data integrity, careless responders (longest or average length of consecutive identical responses was $\pm 3 \mathrm{SD}$ of the respective sample mean) in the derivation sample $(n=27)$, longitudinal- $(n=5)$, and psychiatric validation samples $(n=0)$ were excluded from further analyses using the Careless package [18]. The final sample size of the derivation sample was $n=511$, of the longitudinal validation sample $n=355$, and of the psychiatric inpatient sample $n=113$.

\section{Other measures}

\section{Depression, Anxiety and Stress Scales-21 (DASS-21)}

The total score of the German version of DASS-21 [19, 20] was included, which assesses psychological distress 
during the past week. Items are rated on a Likert scale of 0 (did not apply to me at all) to 3 (applied to me very much or most of the time). Higher scores indicate greater distress (range 0-63). In clinical and non-clinical samples good psychometric properties of the DASS-21 have been reported [21].

\section{Revised-Green et al. Paranoid Thoughts Scale (R-GPTS)}

Paranoid ideations over the past fortnight were assessed with the total score of the German version of the 18item R-GPTS [22, 23]. Items are rated on a 5-point Likert scale ranging from 0 (not at all) to 4 (totally). Higher scores indicate higher levels of paranoia (score range 0-72). Excellent psychometric properties of the scales have been reported for the English version [22].

\section{WHO (Five) Well-Being Index (WHO-5)}

Well-being over the past 2 weeks was assessed by the German version of the WHO-5 [24, 25]. Items are rated on a 6-point Likert scale ranging from 0 (not present) to 5 (constantly present), with higher scores indicating greater well-being (score range: 0-30). Good psychometric properties have been reported in previous research [26].

\section{Statistical analyses}

All analyses were conducted in $R$ v4.0.3 [27].

Descriptive statistics and associations between variables were tested using bivariate Pearson's correlation coefficients, Chi-square tests $\left(x^{2}\right)$, and unpaired twosample $t$ tests (Welch $\mathrm{t}$-test) when appropriate. We report magnitudes of effect sizes of 0.10 considered "small", those of 0.30 as "medium", and those of 0.50 as "large" according to Cohen [28].

We conducted exploratory factor analysis (EFA) based on polychoric correlations with the maximum likelihood estimator (ML) and oblimin rotation to assess the structure of items and refine the item pool by deleting poorfitting items using the Psych package [29]. Items were then considered for deletion one at a time during EFA based on factor loadings (not loading higher than 0.30 on any factor, or loadings above 0.30 on more than one factor), communalities (<.30), content of items (e.g., theoretically inconsistent or redundant), item dependencies, sharp drop in item loading, and differences in response scale. In addition, items with an overall endorsement of $<10 \%$ across the derivation sample, longitudinal- and psychiatric validation samples were deleted. The number of factors to extract was determined through Empirical Kaiser Criterion (EKC), parallel analysis using polychoric correlations, and ML discrepancy function.

To validate the factor structure of the selected items per subscale, confirmatory factor analysis (CFA) with weighted least square mean and variance adjusted
(WLSMV) estimator was conducted in the longitudinal and psychiatric validation samples using the lavaan package [30]. Model fit was assessed using the Comparative Fit Index (CFI; $\leq .95$ considered as acceptable) and Root Mean Square Error of Approximation (RMSEA; $\leq$ .08 considered as acceptable) following common recommendation [31]. Items, which loaded poorly on the factors in both validation samples, were deleted to arrive at the final version of the respective subscales of the questionnaire. Finally, we used modification indices to identify the best fitting model. Internal consistency of the different subscales with more than two items was determined by calculating McDonald's Omega $(\omega)$ and Cronbach's Alpha ( $\alpha$ ) using the MBESS package (v4.8.0; [32]).

Where appropriate, criterion and construct validity were established by testing differences (using Welch two sample t-tests) and strength of associations (using Pearson's $r$ ) in the derivation sample, respectively. To evaluate criterion validity of COVID-19 mental health impact subscales, we assessed if these subscales were associated with self-reported lifetime mental health diagnosis. In terms of construct validity, the COVID-19 mental health impact-, positive coping-, conspiracy-, and institutional \& political trust subscale scores were correlated with different mental health outcome scores that related to psychological distress (DASS-21; [19]), psychological wellbeing (WHO-5;) [24], and paranoia (R-GPTS;) [22]).

\section{Study Part 2: Research application}

\section{Methods}

\section{Matching}

To obtain a more comparable case-control sample for our research application example, the clinical and nonclinical samples were matched on age, sex, and employment status using $R$ software and the MatchIt (v4.1.0) package [33]. After matching, clinical and non-clinical samples were comparable in age and sex (age: $\mathrm{t}(221.65)=-0.58, p=0.564$; sex: $\left.\mathrm{X}^{2}(2)=1.37, p=0.505\right)$, but differences remained for employment status $\left(\mathrm{X}^{2}(6)=\right.$ 21.98, $p=0.001$ ).

\section{Measures}

Following validation of the $\mathrm{CoPaQ}$, we selected the subscales inquiring about perceived countermeasure necessity and countermeasure compliance as well as COVID-19 contamination anxiety, COVID-19 institutional \& political trust, COVID-19 conspiracy beliefs, and COVID-19 physical health risk factors for our research application example. We further included data on the DASS-21 anxiety subscale and refer to this as 'general anxiety' throughout the manuscript to demarcate this construct from 'COVID-19 contamination anxiety'. Finally, we assessed paranoia using the R-GPTS total score. 


\section{Assessment of group differences}

We conducted Welch two sample $t$ tests and calculated standardised mean differences (SMD) to assess group differences in support of COVID-19 related governmental restrictions and recommendations regarding perceived countermeasure necessity and countermeasure compliance as well as COVID-19 contamination anxiety, COVID-19 institutional \& political trust, COVID-19 conspiracy beliefs, COVID-19 physical health risk factors, general anxiety, and paranoia. To assess robustness of results, also against violations of homoscedasticity, we provide $95 \%$ bootstrapped confidence intervals (95\% CI) of the SMD values using 5000 bootstrapped samples with replacement. All hypothesis testing was two-tailed according to $\alpha=0.05$.

\section{Correlation analysis}

To explore the strength of statistical association between support of public health directives and COVID-19 contamination anxiety, COVID-19 institutional \& political trust, COVID-19 conspiracy beliefs, COVID-19 physical health risk factors, general anxiety, and paranoia in clinical and non-clinical samples separately, we performed bivariate Spearman's rho $(\rho)$ correlation analyses and tested whether the strength of associations differed between the clinical and non-clinical group by conducting Fisher $\mathrm{Z}$ transformations with adapted standard errors for Spearman's $\rho$ [34].

\section{Study Part 1: Questionnaire validation}

\section{Results}

\section{Descriptive statistics}

We provide participant characteristics of the derivation sample, longitudinal validation sample, and psychiatric validation sample in Table 1 . The majority of the psychiatric inpatient sample had received a clinician's confirmed clinical diagnosis based on the International Statistical Classification of Diseases and Related Health Problems, 10th revision (ICD-10) criteria of depression, substance abuse disorder, personality disorder, and anxiety disorder. Comorbidity was high with more than two-third of patients meeting criteria for more than one psychiatric diagnosis (see Supplementary Table 1 for more details).

\section{Exploratory and confirmatory factor analyses}

Standardised oblimin rotated factor loadings of the final items are presented in Table 2. Model fit indices and internal consistency estimates of the respective subscales are presented in Tables 3 and 4, respectively. An overview of item selection decisions and related criteria for each subscale can be found in the Supplementary Material. Items loading on the respective subscales can be summed for further analyses.

\section{Study populations characteristics}

From the first section of the $\mathrm{CoPaQ}$, which aims at characterising participant under study, we decided to omit the answer option "Don't know". We further removed optional questions relating to psychotherapy via telephone or video platforms from the final questionnaire version.

\section{COVID-19 contamination anxiety}

Following criteria of poor fitting items (see Methods section), we deleted two items due to redundancy with similarly worded items. The EKC and parallel analysis indicated a 2-factor solution. During EFA, three additional items were deleted due to low factor loadings, factor cross-loadings and only one item loading onto the second factor. Therefore, a 1-factor solution was tested in a next step and all items were retained in the final model. The factor entailed items related to COVID-19 contamination anxiety (e.g., "I am worried I will infect myself with COVID-19"). Subsequently, CFAs in the longitudinal- and psychiatric validation samples were conducted using the 1-factor 4-item model identified during EFA, which showed a good model fit.

\section{COVID-19 necessity of and compliance with countermeasures}

Theoretical considerations, the EKC, and parallel analysis favoured a 1-factor solution for each of the respective COVID-19 countermeasures. During EFA all items were retained. CFAs in the longitudinal- and psychiatric validation samples provided good to acceptable model fit for the respective COVID-19 hygiene measures- (e.g., "regular washing of hands"), social distancing- (e.g., "cancelling private meetings and family visits"), anxiety buying- (e.g., "soap, detergent, cleaning products, washing powder, etc."), political restrictions- (e.g., "temporary closure of bars, pubs, theatres, cinemas, etc."), and solidarity-based behaviours (e.g., "offering help to close friends and family members") subscales. The three items assessing COVID-19 countermeasure compliance of hygiene measures, social distancing, and curfews were grouped into an overall index since they were relatively independent from each other.

\section{COVID-19 mental health impact}

Poor fitting items were deleted due to poor content fit, dependency or redundancy. The EKC and parallel analysis indicated a three-factor solution. EFA suggested good model fit. Only one additional item was deleted due to high factor cross-loadings. Thereafter, all items were retained in the final model. The first factor entailed items related to COVID-19 post-traumatic stress disorder (PTSD) symptoms (e.g., "have had powerful images or memories that sometimes come into my mind in 
Table 1 Socio-demographics and baseline characteristics of the derivation sample, longitudinal validation sample, and psychiatric inpatient sample

\begin{tabular}{|c|c|c|c|}
\hline & $\begin{array}{l}\text { Derivation sample } \\
(n=511)\end{array}$ & $\begin{array}{l}\text { Longitudinal sample } \\
(n=318)\end{array}$ & $\begin{array}{l}\text { Psychiatric sample } \\
(n=113)\end{array}$ \\
\hline Age, mean (SD) & $30.12(11.15)$ & $30.54(11.28)$ & $43.93(14.64)$ \\
\hline Men sex, $n$ & 110 & 68 & 58 \\
\hline \multicolumn{4}{|l|}{ Employment status, n (\%) } \\
\hline Full-time employed & $114(22.3)$ & $73(23.0)$ & $32(28.3)$ \\
\hline Part-time employed & $72(14.1)$ & $47(14.8)$ & $15(13.3)$ \\
\hline Self-employed & $16(3.1)$ & $11(3.5)$ & $4(3.5)$ \\
\hline Student & $248(48.5)$ & $157(49.4)$ & $11(9.7)$ \\
\hline Retired & $8(1.6)$ & $4(1.3)$ & $17(15.0)$ \\
\hline Caregiver & $2(0.4)$ & $0(0.0)$ & $0(0.0)$ \\
\hline Not employed & $14(2.7)$ & $8(2.5)$ & $26(23.0)$ \\
\hline Other & $37(7.2)$ & $18(5.7)$ & $8(7.1)$ \\
\hline \multicolumn{4}{|l|}{ Self-reported lifetime diagnoses, $n$ (\%) } \\
\hline \multicolumn{4}{|l|}{ Diagnostic categories } \\
\hline Depressive Disorders & $120(23.5)$ & $77(24.2)$ & $93(82.3)$ \\
\hline Bipolar Disorders & $5(1.0)$ & $3(0.9)$ & $11(9.7)$ \\
\hline Psychotic Disorders & $3(0.6)$ & $0(0.0)$ & $17(15.0)$ \\
\hline Anxiety Disorders & $62(12.1)$ & $36(11.3)$ & $30(26.5)$ \\
\hline Post-Traumatic Stress Disorder & $26(5.1)$ & $17(5.3)$ & $18(15.9)$ \\
\hline Obsessive-Compulsive and Related Disorders & $7(1.4)$ & $7(2.2)$ & $6(5.3)$ \\
\hline Eating Disorders & $28(5.5)$ & $14(4.4)$ & $17(15.0)$ \\
\hline Substance-Related and Addictive Disorders & $9(1.8)$ & $3(0.9)$ & $31(27.4)$ \\
\hline Attention-Deficit/Hyperactivity Disorder & $15(2.9)$ & $8(2.5)$ & $6(5.3)$ \\
\hline Somatoform Disorders & $4(0.8)$ & $2(0.6)$ & $7(6.2)$ \\
\hline Personality Disorders & $14(2.7)$ & $7(2.2)$ & $22(19.5)$ \\
\hline Autism Spectrum Disorder & $4(0.8)$ & $3(0.9)$ & $8(7.1)$ \\
\hline Dementia & $0(0.0)$ & $0(0.0)$ & $2(1.8)$ \\
\hline
\end{tabular}

$\mathrm{n}$ indicates the number of participants

SD Standard Deviation

which I feel the experience of the COVID-19 pandemic is happening again in the here and now"), the second factor depicted COVID-19 sleep disturbance symptoms (e.g., "difficulty sleeping through the night"), and the third factor entailed items related to COVID-19 substance abuse (e.g., "have smoked considerably more cigarettes than usual"). Subsequently, CFAs in the longitudinal- and psychiatric validation samples were conducted using the 3-factor 13-item model identified during EFA, which did not provide a good model fit. Modification indices indicated dropping one additional poor fitting item, which was removed and the CFAs repeated. Now model fit indices suggested mixed results in the longitudinal validation sample with good to only adequate model fit according to RMSEA and CFI, respectively. Model fit in the psychiatric validation sample was good.

\section{COVID-19-specific stressors impact}

First, the not applicable answer option was recoded as zero and removed from in the final validated questionnaire version. Items with poorly fitting content were then deleted. In addition, items related to the ability to distance oneself from the stressors were deleted due to item dependency. As each stressor (e.g., "childcare", "being in quarantine" or "being in home office") can occur relatively independently, no factor analysis was applied for COVID-19-specific stressors, so the remaining items can be summed to an index.

\section{COVID-19 positive coping}

Three items were deleted due to poor item-scale content fit. The EKC and parallel analysis indicated a threefactor solution, which we evaluated in the subsequent EFA. During EFA, one additional item was deleted due 
Table 2 Final items and factor loadings from EFA and CFAs in our three samples

\begin{tabular}{|c|c|c|c|}
\hline & $\begin{array}{l}\text { Derivation } \\
\text { sample }\end{array}$ & $\begin{array}{l}\text { Longitudinal } \\
\text { validation } \\
\text { sample }\end{array}$ & $\begin{array}{l}\text { Psychiatric } \\
\text { validation } \\
\text { sample }\end{array}$ \\
\hline & $\begin{array}{l}\text { EFA } \\
\text { Loadings }\end{array}$ & $\begin{array}{l}\text { CFA } \\
\text { Loadings }\end{array}$ & $\begin{array}{l}\text { CFA } \\
\text { Loadings }\end{array}$ \\
\hline \multicolumn{4}{|l|}{ COVID-19 contamination anxiety } \\
\hline I will infect myself with COVID-19 & 0.54 & 0.54 & 0.54 \\
\hline Please indicate how likely you think it is that you will be infected with COVID-19. & 0.74 & 0.58 & 0.77 \\
\hline people close to me are infected with COVID-19. & 0.88 & 0.89 & 0.65 \\
\hline I will infect other people with COVID-19. & 0.79 & 0.72 & 0.73 \\
\hline \multicolumn{4}{|l|}{ COVID-19 hygiene measures } \\
\hline keeping at least $1.5 \mathrm{~m}$ distance from other people & 0.67 & 0.67 & 0.63 \\
\hline coughing or sneezing into the crook of your arm or into a handkerchief & 0.71 & 0.52 & 0.54 \\
\hline not touching mouth, eyes or nose with hands & 0.81 & 0.80 & 0.58 \\
\hline regular washing of hands & 0.93 & 0.79 & 0.63 \\
\hline washing hands extensively (for at least $30 \mathrm{~s}$ ) & 0.92 & 0.82 & 0.79 \\
\hline increased disinfection of hands and objects. & 0.68 & 0.65 & 0.68 \\
\hline \multicolumn{4}{|l|}{ COVID-19 social distancing } \\
\hline cancelling private meetings and family visits & 0.82 & 0.79 & 0.76 \\
\hline cancelling trips to other cities & 0.90 & 0.85 & 0.69 \\
\hline avoiding visits to canteens and restaurants & 0.87 & 0.79 & 0.82 \\
\hline $\begin{array}{l}\text { avoiding touching (e.g. shaking hands or hugging) when greeting or saying goodbye to } \\
\text { other people }\end{array}$ & 0.78 & 0.74 & 0.47 \\
\hline moving your work to home office & 0.71 & 0.64 & 0.39 \\
\hline \multicolumn{4}{|l|}{ COVID-19 anxiety buying } \\
\hline soap, detergent, cleaning products, washing powder, etc. & 0.88 & 0.84 & 0.89 \\
\hline food (vegetables, lentils, rice, pasta...) & 0.94 & 0.88 & 0.95 \\
\hline water (20 I per person) & 0.79 & 0.73 & 0.85 \\
\hline toilet paper & 0.84 & 0.82 & 0.92 \\
\hline cash & 0.59 & 0.53 & 0.62 \\
\hline \multicolumn{4}{|l|}{ COVID-19 political restrictions } \\
\hline temporary closures of kindergartens, schools and universities & 0.84 & 0.80 & 0.85 \\
\hline temporary border closures & 0.74 & 0.67 & 0.71 \\
\hline temporary closures of playgrounds & 0.85 & 0.75 & 0.90 \\
\hline temporary closure of bars, pubs, theatres, cinemas, etc. & 0.87 & 0.78 & 0.72 \\
\hline temporary curfews & 0.80 & 0.76 & 0.82 \\
\hline \multicolumn{4}{|l|}{ COVID-19 solidarity-based behaviours } \\
\hline donating blood & 0.63 & 0.70 & 0.54 \\
\hline $\begin{array}{l}\text { supporting people at risk, such as shopping for them or staying at home to protect people at } \\
\text { risk to protect people at risk }\end{array}$ & 0.86 & 0.77 & 0.88 \\
\hline supporting people who are experiencing existential hardship due to the current situation & 0.87 & 0.79 & 0.86 \\
\hline offering help to close friends and family members & 0.81 & 0.71 & 0.57 \\
\hline donating blood & 0.77 & 0.80 & 0.65 \\
\hline \multicolumn{4}{|l|}{ COVID-19 post-traumatic stress disorder symptoms } \\
\hline $\begin{array}{l}\text { have had upsetting dreams that replay part of the experience of the COVID-19 pandemic or } \\
\text { are clearly related to it }\end{array}$ & 0.51 & 0.61 & 0.60 \\
\hline $\begin{array}{l}\text { have had powerful images or memories that sometimes come into my mind in which I feel } \\
\text { the experience of the COVID-19 pandemic is happening again in the here and now }\end{array}$ & 0.75 & 0.72 & 0.75 \\
\hline
\end{tabular}


Table 2 Final items and factor loadings from EFA and CFAs in our three samples (Continued)

\begin{tabular}{|c|c|c|c|}
\hline & \multirow{2}{*}{$\begin{array}{l}\text { Derivation } \\
\text { sample } \\
\text { EFA } \\
\text { Loadings }\end{array}$} & \multirow{2}{*}{$\begin{array}{l}\text { Longitudinal } \\
\text { validation } \\
\text { sample } \\
\text { CFA } \\
\text { Loadings }\end{array}$} & \multirow{2}{*}{$\begin{array}{l}\text { Psychiatric } \\
\text { validation } \\
\text { sample } \\
\text { CFA } \\
\text { Loadings }\end{array}$} \\
\hline & & & \\
\hline $\begin{array}{l}\text { have avoided internal reminders of the experience of the COVID-19 pandemic (e.g. thoughts, } \\
\text { feeling, or physical sensations) }\end{array}$ & 0.97 & 0.82 & 0.64 \\
\hline $\begin{array}{l}\text { have avoided external reminders of the experience of the COVID-19 pandemic (e.g. people, } \\
\text { places, conversations, objects, activities, or situations) }\end{array}$ & 0.92 & 0.73 & 0.79 \\
\hline have been "super-alert", watchful, or on guard & 0.45 & 0.56 & 0.67 \\
\hline \multicolumn{4}{|l|}{ COVID-19 sleep disturbances } \\
\hline difficulty falling asleep (< 30 min) & 1.02 & 0.82 & 0.88 \\
\hline difficulty sleeping through the night & 0.77 & 0.87 & 0.79 \\
\hline early morning awakening & 0.70 & 0.74 & 0.74 \\
\hline \multicolumn{4}{|l|}{ COVID-19 substance use } \\
\hline have consumed substantially more alcohol than usual. & 0.68 & & \\
\hline have smoked considerably more cigarettes than usual & 0.86 & 0.61 & 0.66 \\
\hline $\begin{array}{l}\text { have consumed considerably more drugs (e.g. tranquilizers, sleeping pills or stimulants) than } \\
\text { usual }\end{array}$ & 0.63 & 0.63 & 0.61 \\
\hline have felt a strong desire to consume addictive substances (alcohol, cigarettes, drugs) & 0.87 & 0.90 & 0.84 \\
\hline have not been able to control my use of addictive substances (alcohol, cigarettes, drugs) & 0.90 & 0.58 & 0.50 \\
\hline \multicolumn{4}{|l|}{ COVID-19 daytime structure } \\
\hline have maintained a regular daily routine & 0.90 & 0.81 & 0.76 \\
\hline have planned the day as detailed as possible & 0.80 & 0.79 & 0.95 \\
\hline have integrated sports and exercise into my daily life & 0.39 & 0.55 & 0.58 \\
\hline \multicolumn{4}{|l|}{ COVID-19 social contacts } \\
\hline have maintained my social contacts (telephone, visits or video chats) & 0.47 & 0.68 & 0.65 \\
\hline have enjoyed the time together with people close to me & 0.74 & 0.50 & 0.50 \\
\hline \multicolumn{4}{|l|}{ COVID-19 inner resources } \\
\hline have sought stability in faith and/or religion & 0.45 & & \\
\hline have focused on my inner strengths, resources, abilities and talents & 0.59 & 0.87 & 0.72 \\
\hline have changed my attitudes about what is really important to me in life & 0.64 & 0.39 & 0.70 \\
\hline \multicolumn{4}{|l|}{ COVID-19 political and institutional trust } \\
\hline have had the feeling that the political leadership was standing up for me & 0.84 & 0.81 & 0.67 \\
\hline have perceived democracy as an effective form of government & 0.85 & 0.75 & 0.77 \\
\hline have had the feeling that public institutions (e.g. police, judiciary) can be relied upon & 0.78 & 0.79 & 0.82 \\
\hline $\begin{array}{l}\text { have had the feeling that news and reports on the COVID-19 pandemic are being deliberately } \\
\text { withheld }\end{array}$ & 0.84 & 0.86 & 0.30 \\
\hline have perceived politicians as trustworthy & 0.65 & 0.61 & 0.77 \\
\hline \multicolumn{4}{|l|}{ COVID-19 conspiracy beliefs } \\
\hline $\begin{array}{l}\text { have had the feeling that false reports or untruths about the COVID-19 pandemic are being } \\
\text { deliberately disseminated on public broadcasting (e.g. radio and television stations). }\end{array}$ & 0.62 & 0.49 & 0.62 \\
\hline have had the belief that there are alternative or secret explanations for current events & 0.80 & 0.89 & 0.84 \\
\hline $\begin{array}{l}\text { have had the belief that there is a relation between what is happening and the production } \\
\text { and testing of biological weapons }\end{array}$ & 0.88 & 0.72 & 0.77 \\
\hline $\begin{array}{l}\text { have had the belief that what is happening here is the effect of a struggle or competition } \\
\text { between different superpowers }\end{array}$ & 0.95 & 0.77 & 0.84 \\
\hline have had the belief that this infection serves to deliberately reduce the world population, & 0.85 & 0.64 & 0.88 \\
\hline
\end{tabular}


Table 2 Final items and factor loadings from EFA and CFAs in our three samples (Continued)

\begin{tabular}{|c|c|c|c|}
\hline & $\begin{array}{l}\text { Derivation } \\
\text { sample }\end{array}$ & $\begin{array}{l}\text { Longitudinal } \\
\text { validation } \\
\text { sample }\end{array}$ & $\begin{array}{l}\text { Psychiatric } \\
\text { validation } \\
\text { sample }\end{array}$ \\
\hline & $\begin{array}{l}\text { EFA } \\
\text { Loadings }\end{array}$ & $\begin{array}{l}\text { CFA } \\
\text { Loadings }\end{array}$ & $\begin{array}{l}\text { CFA } \\
\text { Loadings }\end{array}$ \\
\hline \multicolumn{4}{|l|}{ COVID-19 social cohesion } \\
\hline there is greater solidarity and cohesion in our society. & 0.84 & 0.79 & \\
\hline I am an integral part of our society or community. & 0.61 & 0.61 & \\
\hline our nation is growing closer together. & 0.93 & 0.79 & \\
\hline
\end{tabular}

to low factor loadings. The first factor entailed items related to keeping a daytime structure (e.g., "have planned the day as detailed as possible"), the second factor depicted positive coping items in terms of social contacts (e.g., "have maintained my social contacts (telephone, visits or video chats)"), and the third factor entailed items related to inner strength (e.g., "have changed my attitudes about what is really important to me in life") during the pandemic. Subsequently, CFAs in the longitudinal- and psychiatric validation samples were conducted using the 3-factor 9-item model identified during EFA, which resulted in a poor model fit. Two additional items from the social contacts and inner strength subscales were deleted due to poor model and content fit. The subsequent model fit was good across samples.

\section{COVID-19 institutional \& political trust}

First, we deleted one item due to item content. One item was reversed coded. The EKC and parallel analysis indicated a one-factor solution. During EFA all items were retained and related to political and institutional trust (e.g., "have had the feeling that the political leadership was standing up for me"). Subsequently, CFAs in the validation samples were conducted using the 1-factor 5item model identified during EFA, which provided a poor model fit in the longitudinal validation sample and good model fit in the psychiatric validation sample.

\section{COVID-19 conspiracy beliefs}

We deleted one item due to a different response format. The EKC and parallel analysis indicated a 1-factor solution. During EFA all items were retained. The factor entailed items related to COVID-19 conspiracy beliefs (e.g., "have had the belief that what is happening here is the effect of a struggle or competition between different superpowers"). Subsequently, CFAs in our validation samples were conducted using the 1-factor 5-item model identified during EFA, which provided an acceptable model fit in the longitudinal but not in the psychiatric validation sample.

\section{COVID-19 social cohesion}

First, three items were removed due to item redundancy. The EKC and parallel analysis indicated a one-factor solution. During EFA all items were retained and related

Table 3 Model fit indices of the CFA analyses in the longitudinal validation sample

\begin{tabular}{|c|c|c|c|c|}
\hline \multirow[b]{2}{*}{ Subscale } & \multirow{2}{*}{$\begin{array}{l}\text { Longitudinal validation sample } \\
\text { CFI }\end{array}$} & \multicolumn{3}{|c|}{ Psychiatric validation samples } \\
\hline & & RMSEA & CFI & RMSEA \\
\hline COVID-19 contamination anxiety & 0.996 & 0.039 & 1.000 & $<0.001$ \\
\hline COVID-19 hygiene measures & 0.924 & 0.069 & 1.000 & $<0.001$ \\
\hline COVID-19 social distancing & 1.000 & $<0.001$ & 0.979 & 0.061 \\
\hline COVID-19 anxiety buying & 0.951 & 0.081 & 0.991 & 0.056 \\
\hline COVID-19 political restrictions & 0.993 & 0.045 & 0.955 & 0.107 \\
\hline COVID-19 solidarity-based behaviours & 0.988 & 0.037 & 1.000 & $<0.001$ \\
\hline COVID-19 mental health subscale & 0.938 & 0.038 & 0.994 & 0.011 \\
\hline COVID-19 positive coping & 0.979 & 0.049 & 0.965 & 0.066 \\
\hline COVID-19 institutional \& political trust & 0.931 & 0.138 & 0.997 & 0.027 \\
\hline COVID-19 conspiracy beliefs & 0.924 & 0.069 & 0.880 & 0.119 \\
\hline COVID-19 social cohesion & 1.000 & $<0.001$ & n.a. & n.a. \\
\hline
\end{tabular}

CFI Comparative Fit Index, RMSEA Root Mean Square Error of Approximation, n.a. Heywood case 
Table 4 Internal consistency estimates of the different CoPaQ subscales based on McDonald's Omega and Cronbach's Alpha in our three samples

\begin{tabular}{|c|c|c|c|c|c|c|}
\hline \multirow[b]{2}{*}{ Subscale } & \multicolumn{2}{|c|}{ Derivation sample } & \multicolumn{2}{|c|}{ Longitudinal validation sample } & \multicolumn{2}{|c|}{ Psychiatric validation sample } \\
\hline & $\omega$ & $a$ & $\omega$ & $a$ & $\omega$ & a \\
\hline COVID-19 contamination anxiety & 0.79 & 0.78 & 0.79 & 0.77 & 0.77 & 0.77 \\
\hline COVID-19 hygiene measures & 0.83 & 0.83 & 0.86 & 0.84 & 0.81 & 0.81 \\
\hline COVID-19 social distancing & 0.88 & 0.87 & 0.87 & 0.87 & 0.76 & 0.75 \\
\hline COVID-19 anxiety buying & 0.86 & 0.85 & 0.88 & 0.87 & 0.93 & 0.92 \\
\hline COVID-19 political restrictions & 0.88 & 0.88 & 0.86 & 0.86 & 0.90 & 0.90 \\
\hline COVID-19 solidarity-based behaviours & 0.82 & 0.82 & 0.87 & 0.86 & 0.81 & 0.81 \\
\hline COVID-19 countermeasure compliance & n.a. & n.a. & n.a. & n.a. & n.a. & n.a. \\
\hline COVID-19 PTSD symptoms & 0.78 & 0.78 & 0.83 & 0.81 & 0.82 & 0.82 \\
\hline COVID-19 sleep disturbance & 0.83 & 0.81 & 0.87 & 0.85 & 0.85 & 0.84 \\
\hline COVID-19 substance abuse & 0.77 & 0.75 & 0.80 & 0.77 & 0.76 & 0.74 \\
\hline COVID-19-specific stressor impact & n.a. & n.a. & n.a. & n.a. & n.a. & n.a. \\
\hline COVID-19 daytime structure & 0.72 & 0.69 & 0.76 & 0.75 & 0.80 & 0.79 \\
\hline COVID-19 social contacts & n.a. & n.a. & n.a. & n.a. & n.a. & n.a. \\
\hline COVID-19 inner strength & n.a. & n.a. & n.a. & n.a. & n.a. & n.a. \\
\hline COVID-19 institutional \& political trust & 0.87 & 0.86 & 0.88 & 0.88 & 0.81 & 0.79 \\
\hline COVID-19 conspiracy beliefs & 0.82 & 0.82 & 0.79 & 0.78 & 0.90 & 0.89 \\
\hline COVID-19 social cohesion & 0.80 & 0.79 & 0.77 & 0.76 & n.a. & n.a. \\
\hline
\end{tabular}

$\omega$ indicates McDonald's Omega. a indicates Cronbach's Alpha

n.a. not applicable

to COVID-19 social cohesion (e.g., "our nation is growing closer together"). Subsequently, CFAs in our validation samples were conducted using the 1-factor 3-item model identified during EFA, which provided a good model fit in the longitudinal sample, but resulted in model misspecification in the psychiatric validation sample.

\section{Omitted subscales}

The theoretically constructed subscales of COVID-19 media use (e.g., "have carried out an increased amount of research about the COVID-19 pandemic via the Internet"), COVID-19 interpersonal conflicts (e.g., "have had more physical arguments (e.g. beating, boxing, kicking) with people close to me"), and COVID-19 paranoid ideations (e.g., "have had the belief that the corona-virus was introduced to get at people like me") were omitted from the $\mathrm{CoPaQ}$ measure due to poor model fit during EFA.

\section{Internal consistency}

Overall, the CoPaQ subscale factors' internal consistency estimates ranged from acceptable to excellent in our derivation-, longitudinal- and psychiatric samples.

\section{Construct and criterion validity}

The COVID-19-specific stressor and mental health impact subscales were associated with all mental health outcomes and most strongly with greater psychological distress; the COVID-19 positive coping subscales were most strongly associated with greater psychological wellbeing; and the COVID-19 institutional \& political trust and COVID-19 conspiracy beliefs subscales were most strongly associated with lower and higher paranoia levels, respectively (see Table 5 ). Table 6 shows the results for the evaluation of criterion validity, which shows that the COVID-19 mental health impact subscales were more strongly endorsed if the participant had selfreported a lifetime mental health diagnosis.

\section{Study Part 2: Research application}

\section{Results}

\section{Assessment of group differences}

Psychiatric inpatients indicated greater support of COVID-19 public health directives compared to nonclinical individuals in terms of the perception of necessity of hygiene measures $(\mathrm{t}(199.93)=-2.84 ; p<0.01,95 \%$ $\left.\mathrm{CI}_{\text {bootstrappedSMD }}=-0.60,-0.12\right)$, political restrictions $\left(\mathrm{t}(208.92)=-3.23 ; p<0.01 ; 95 \% \mathrm{CI}_{\text {bootstrappedSMD }}=-0.66\right.$, -0.18), and overall compliance with countermeasures $\left(\mathrm{t}(201.13)=-2.07 ; p=0.04 ; 95 \% \mathrm{CI}_{\text {bootstrappedSMD }}=-0.52\right.$, - 0.01). No difference between groups was evident for perception of necessity of social distancing $(\mathrm{t}(198.19)=-0.87$; $\left.p=0.38 ; 95 \% \mathrm{CI}_{\text {bootstrappedSMD }}=-0.37,0.15\right)$. 
Table 5 Correlations between CoPaQ subscale scores and mental health outcomes

\begin{tabular}{llll}
\hline CoPaQ subscales & DASS-21 Total & WHO-5 Total & R-GPTS Total \\
\hline COVID-19-specific stressor impact & $.49^{* *}$ & $-.41^{* *}$ & $.34^{* *}$ \\
COVID-19 mental health impact & & & $-.32^{* *}$ \\
PTSD symptoms & $.42^{* *}$ & $-.37^{* *}$ & $.34^{* *}$ \\
Sleep disturbance & $.47^{* *}$ & $-.26^{* *}$ & $.30^{* *}$ \\
Substance abuse & $.29^{* *}$ & & $.12^{* *}$ \\
COVID-19 positive coping & & $.33^{* *}$ & -.05 \\
Daytime structure & $-.19^{* *}$ & $.40^{* *}$ & $-16^{* *}$ \\
Social contacts & $-.33^{* *}$ & $.32^{* *}$ & .04 \\
Inner strength & $-.18^{* *}$ & $.14^{* *}$ & $-.13^{* *}$ \\
COVID-19 institutional \& political trust & $-.11^{*}$ & -.05 & $.30^{* *}$ \\
COVID-19 conspiracy beliefs & $.14^{* *}$ &
\end{tabular}

DASS-21 Depression, Anxiety, Stress Scales-21, WHO-5 WHO-5 Well-being Index (WHO), R-GPTS Revised-Green et al. Paranoid Thoughts Scale

* indicates $p<.05 .{ }^{* *}$ indicates $p<.01$

Further, COVID-19 contamination anxiety, COVID-19 institutional \& political trust, and COVID-19 conspiracy beliefs did not differ between groups, whereas psychiatric inpatients indicated higher levels of general anxiety and COVID-19 physical health risk factors compared to non-clinical individuals with medium to high effect sizes (see Table 7).

\section{Correlational analysis}

Bivariate Spearman's $\rho$ correlations of support of public health directives with general anxiety, COVID-19 physical health risk factors, COVID-19 contamination anxiety, paranoia, COVID-19 institutional \& political trust, and COVID-19 conspiracy beliefs are displayed in Table 8.

Necessity and compliance of COVID-19 public health countermeasure were positively associated with COVID19 contamination anxiety and COVID-19 institutional \& political trust in the clinical (Spearman's $\rho$ coefficients ranged from .19 to .36) and non-clinical group (Spearman's $\rho$ coefficients ranged from .36 to .64). Here, the strengths of associations were observed to be stronger in the non-clinical than the clinical sample. The difference in correlations was significant for COVID-19 institutional \& political trust (Fisher's $\mathrm{Z}_{\mathrm{Hygiene}}$ measures $=-4.30$, $p<0.01 ; \mathrm{Z}_{\text {Social distancing }}=-3.61, p<0.01 ; \mathrm{Z}_{\text {Political restric- }}$ tions $\left.=-3.65, p<0.01 ; Z_{\text {Compliance }}=-2.56, p=0.01\right)$ but not for contamination anxiety (Fisher's $\mathrm{Z}_{\mathrm{Hygiene}}$ measures $=$ $-0.16, p=0.87 ; Z_{\text {Social distancing }}=-1.05, p=0.29 ; Z_{\text {Political }}$ restrictions $=-0.56, p=0.57 ; \mathrm{Z}_{\text {Compliance }}=-1.50, p=0.13$ ). General anxiety was only associated significantly with the perception of necessity of political restrictions in the psychiatric inpatient sample $\left(\rho_{\text {Clinical sample }}=.31 ; \rho_{\text {Non-cli- }}\right.$ nical sample $=.07)$. However, this difference in strength of associations was not statistically significant $\left(Z_{\text {Political re- }}\right.$ strictions $=-1.80, p=0.07)$. In the non-clinical sample only, COVID-19 conspiracy beliefs were negatively associated with COVID-19 countermeasure necessity and compliance (absolute $\rho$ coefficients ranged from 0.30 to 0.40 ). Fisher's $\mathrm{Z}$ tests indicated that these associations were significantly stronger in the non-clinical than clinical group for the perception of necessity of social distancing $(\mathrm{Z}=2.33, p=0.02)$ and political restrictions $(\mathrm{Z}=$ 2.36, $p=0.02)$ but not for hygiene measures $(Z=1.72$, $p=0.08)$ or overall compliance $(\mathrm{Z}=1.21, p=0.23)$. In

Table 6 T-tests comparing CoPaQ mental health and disease worries subscale scores for relevant variables to establish criterion validity

\begin{tabular}{|c|c|c|c|c|c|c|c|}
\hline & \multirow[b]{2}{*}{$\mathrm{n}$} & \multicolumn{2}{|c|}{ COVID-19 PTSD symptoms } & \multicolumn{2}{|c|}{ COVID-19 sleep disturbance } & \multicolumn{2}{|c|}{ COVID-19 substance use } \\
\hline & & Mean (SD) & $\mathbf{t}$ & Mean (SD) & $\mathbf{t}$ & Mean (SD) & $\mathbf{t}$ \\
\hline \multicolumn{8}{|c|}{ Mental Health Diagnosis } \\
\hline No & 340 & $2.85(3.51)$ & $-2.20^{*}$ & $2.66(3.37)$ & $-4.54^{* * *}$ & $0.82(1.90)$ & $-3.30^{* *}$ \\
\hline Yes & 171 & $3.71(4.46)$ & & 4.16 (3.59) & & 1.71 (3.27) & \\
\hline
\end{tabular}

$P$ values based on Welch two sample $t$ test

$S D$ Standard Deviation

${ }^{*} p<.05,{ }^{* *} p<.01,{ }^{* * *} p<.001$ 
Table 7 Descriptive statistics and differences of the independent variables

\begin{tabular}{|c|c|c|c|c|c|c|c|}
\hline \multirow[b]{2}{*}{ Subscales } & \multicolumn{2}{|c|}{ Clinical sample } & \multicolumn{2}{|c|}{ Non-clinical sample } & \multirow[b]{2}{*}{$p$} & \multirow[b]{2}{*}{ SMD } & \multirow[b]{2}{*}{ 95\% $\mathrm{Cl}_{\text {bootstrapped }}$} \\
\hline & Mean (SD) & range & Mean (SD) & range & & & \\
\hline \multicolumn{8}{|l|}{ DASS-21 } \\
\hline General anxiety & $12.02(9.98)$ & $0-40$ & $6.58(6.88)$ & $0-28$ & $<0.001^{* * *}$ & -0.605 & $-0.83,-0.38$ \\
\hline \multicolumn{8}{|l|}{ R-GPTS } \\
\hline Paranoia & $10.04(13.10)$ & $0-61$ & $9.96(9.57)$ & $0-47$ & 0.958 & -0.007 & $-0.25,0.28$ \\
\hline \multicolumn{8}{|l|}{ CoPaQ } \\
\hline COVID-19 conspiracy beliefs & $3.49(4.76)$ & $0-19$ & $3.50(4.10)$ & $0-16$ & 0.976 & 0.004 & $-0.25,0.28$ \\
\hline COVID-19 institutional \& political trust & $11.43(4.88)$ & $0-20$ & $10.88(6.20)$ & $0-20$ & 0.461 & -0.098 & $-0.36,0.16$ \\
\hline COVID-19 physical health risk factors & $0.98(1.17)$ & $0-5$ & $0.62(1.19)$ & $0-7$ & $0.022^{*}$ & -0.304 & $-0.59,-0.04$ \\
\hline COVID-19 contamination anxiety & $5.93(3.46)$ & $0-16$ & $6.61(3.94)$ & $0-16$ & 0.169 & 0.183 & $-0.07,0.44$ \\
\hline
\end{tabular}

SD Standard Deviation, SMD Standardised Mean Difference, $\mathrm{Cl}_{\text {bootstrapped }}$ Confidence Interval bootstrapped $_{\text {(5000 times) }}$

both samples, evidence for associations with paranoia and COVID-19 physical health risk factors was either absent or very small (absolute $\rho$ coefficients ranged from 0.01 to 0.18$)$.

\section{Discussion}

Understanding the psychosocial impact of the COVID19 pandemic in different study populations has become an international priority. In this study, we report first findings from the assessment of psychiatric inpatients and non-clinical subjects using the $\mathrm{CoPaQ}$ tool that was designed to measure key psychosocial aspects of the pandemic including contamination anxiety, countermeasure necessity and compliance, mental health impact, COVID-19-specific stressor impact, social media usage, interpersonal conflicts, paranoid ideations, institutional \& political trust, conspiracy beliefs, and social cohesion. The questionnaire was developed for application in different study populations, has been published on the Open Science Framework and is currently available in 11 languages. Here, we conducted a psychometric evaluation of the scale in its German version using data from a longitudinal sample of non-clinical individuals and psychiatric inpatients. Factor analyses indicated that 12 out of 16 extracted subscales showed acceptable to good model fit indices, internal consistency estimates and, where appropriate, construct and criterion validity in at least one validation sample. Therefore, these subscales were retained in the final version of the $\mathrm{CoPaQ}$. Overall, the final version of the $\mathrm{CoPaQ}$ represents a valid measure that can help to better understand key aspects affected by the pandemic as illustrated by our research application example.

Psychometric validation in the longitudinal nonclinical and psychiatric validation samples demonstrated key strengths and limitations of individual $\mathrm{CoPaQ}$ subscales. The theoretically constructed 'COVID-19 social

Table 8 Spearman's $\rho$ correlations in the clinical and non-clinical samples

\begin{tabular}{|c|c|c|c|c|c|c|c|c|}
\hline \multirow[b]{3}{*}{ Subscales } & \multicolumn{4}{|c|}{ Clinical sample } & \multicolumn{4}{|c|}{ Non-clinical sample } \\
\hline & \multicolumn{4}{|c|}{ Perception of necessity of } & \multicolumn{4}{|c|}{ Perception of necessity of } \\
\hline & $\begin{array}{l}\text { Hygiene } \\
\text { measures }\end{array}$ & $\begin{array}{l}\text { Social } \\
\text { distancing }\end{array}$ & $\begin{array}{l}\text { Political } \\
\text { restrictions }\end{array}$ & Compliance & $\begin{array}{l}\text { Hygiene } \\
\text { measures }\end{array}$ & $\begin{array}{l}\text { Social } \\
\text { distancing }\end{array}$ & $\begin{array}{l}\text { Political } \\
\text { restrictions }\end{array}$ & Compliance \\
\hline General anxiety & .14 & .12 & $.31^{* *}$ & .15 & .09 & .06 & .07 & -.07 \\
\hline Paranoia & -.11 & -.03 & .05 & -.01 & -.09 & -.02 & .07 & -.15 \\
\hline $\begin{array}{l}\text { Institutional \& political } \\
\text { trust }\end{array}$ & .16 & $.19^{*}$ & $.20^{*}$ & $.23^{*}$ & $.64^{* *}$ & $.60^{* *}$ & $.61^{* *}$ & $.53^{* *}$ \\
\hline $\begin{array}{l}\text { Contamination } \\
\text { anxiety }\end{array}$ & $.34^{* *}$ & $.36^{* *}$ & $.29^{* *}$ & $.19^{*}$ & $.36^{* *}$ & $.48^{* *}$ & $.36^{* *}$ & $.38^{* *}$ \\
\hline $\begin{array}{l}\text { Physical health risk } \\
\text { factors }\end{array}$ & .07 & .07 & .06 & .10 & .02 & -.12 & -.18 & -.08 \\
\hline Conspiracy beliefs & -.07 & -.10 & -.06 & -.14 & $-.30^{* *}$ & $-.40^{* *}$ & $-.37^{* *}$ & $-.30^{* *}$ \\
\hline
\end{tabular}

* indicates $p<.05 .{ }^{* *}$ indicates $p<.01$ 
media usage', 'COVID-19 interpersonal conflicts', and 'COVID-19 paranoid ideations' subscales were omitted from the final questionnaire version due to poor psychometric properties during EFA. In the longitudinal validation sample, the $\mathrm{CoPaQ}$ subscales of 'COVID-19 hygiene measures', 'COVID-19 anxiety buying', 'COVID19 mental health', and 'COVID-19 conspiracy beliefs' only showed at least acceptable model fit for one of two indices and 'COVID-19 institutional \& political trust' had poor model fit overall, which questions the utility of these subscales for repeated measurement designs. Similarly, in the psychiatric validation sample the subscale of 'COVID-19 political restrictions' showed acceptable model fit only according to CFI but not RMSEA and poor model fit was observed for the subscales of 'COVID-19 conspiracy beliefs' and 'COVID-19 social cohesion' limiting their valid application for this study population. However, internal consistency estimates of all subscales ranged from acceptable to excellent across samples. Moreover, where applicable we observed evidence for construct and criterion validity for the subscales of 'COVID-19-specific stressor impact', 'COVID19 mental health impact', 'COVID-19 positive coping', 'COVID-19 institutional \& political trust', and 'COVID19 conspiracy beliefs'. Future research is needed to evaluate the psychometric properties of the $\mathrm{CoPaQ}$ in different languages/cultures and study populations of interest during the current pandemic (e.g., frontline health workers, vulnerable individuals with a physical condition at risk of a severe course of COVID-19, or caretakers).

In order to present a first use case for which new tools are required for addressing a research question specific for the COVID-19 pandemic, we investigated whether psychiatric inpatients may have lower compliance with preventive countermeasures as previously discussed by some authors $[5,6]$. Contrary to this view, our results indicate that the support of public health directives to contain the spread of the coronavirus was indeed greater in psychiatric inpatients primarily admitted for major depressive-, substance abuse-, personality-, and anxiety disorders, compared to age-, sex-, and employment status matched non-clinical individuals. Results may be regarded as preliminary evidence against the hypothesis that higher SARS-Cov-2 infection rates in psychiatric patients are due to lower adherence to countermeasures $[5,6]$. Findings from correlational analyses indicated that particularly trust in institutions \& politics as well as contamination anxiety were associated with increased levels of support of public health directives during the pandemic in clinical- and non-clinical individuals, which is in line with previous research [7-10]. However, general anxiety was additionally associated with increased support of public health directives only in the clinical sample. This could indicate general anxiety is a putative driver of the increased reported support of countermeasures in psychiatric patients, that we observed in our sample. It is important to note, however, that these results are restricted by non-significant correlational differences between samples. Additionally, the psychiatric inpatient setting may explain part of our findings since non-acceptance and non-compliance may likely lead to hospital discharge, social pressure from hospital staff and fellow patients, and a greater uncontrollable risk of infection in a relatively crowded hospital environment. In addition, paper-pencil questionnaire completion in the psychiatric patient sample may have contributed to greater socially desirable responses compared to online completion in the non-clinical group. Moreover, our findings and conclusions may not be extended to other diagnoses (e.g., a sample consisting of patients with psychotic disorders only) or treatment settings (e.g., outpatients).

\section{Limitations}

There are obvious methodological limitations of our study: First, we have assessed construct validity and criterion validity for some but not all subscales of the $\mathrm{CoPaQ}$. Future studies should test whether the other subscales assess what they are intended to measure. Second, since we applied the German version of the $\mathrm{CoPaQ}$, generalisability of results to other languages/cultures is limited, which needs to be addressed in future research. Wider distribution of the $\mathrm{CoPaQ}$ and its translated versions in our open science approach would leverage such transcultural studies. Third, CFAs were based on relatively small sample sizes, which may have affected the robustness of results. As such, replications in larger study cohorts are needed. Fourth, the clinical and nonclinical samples are unlikely to fully represent the populations from which they were drawn. Finally, research needs to assess the CoPaQ's predictive validity, testretest reliability, and conduct evaluations in other study populations.

\section{Conclusion}

Notwithstanding these caveats, the $\mathrm{CoPaQ}$ is a comprehensive, yet relatively brief self-assessment tool that covers a broad spectrum of pressing psychosocial topics during the current COVID-19 pandemic. The scale has the potential to facilitate the investigation of psychosocial reactions to the pandemic and could help assess the impact of potential future epidemics and pandemics if adapted accordingly. Our use case highlights its potential to untangle complex psychosocial aspects regarding levels of support of COVID-19 countermeasures in psychiatric inpatients and non-clinical individuals. Our findings stress the importance of transparent public health 
communication to foster trust in institutions and politics as well as inform the public about the potential contagiousness of the coronavirus to increase acceptance and adherence with the different public health directives in clinical and non-clinical groups during the current pandemic.

\begin{abstract}
Abbreviations
CoPaQ: COVID-19 Pandemic Mental Health Questionnaire; OSF: Open Science Framework; EFA: Explorative factor analysis; CFA: Confirmatory factor analysis; WLSMV: Weighted least square mean and variance adjusted;

CFI: Comparative Fit Index; RMSEA: Root Mean Square Error of Approximation; ML: Maximum likelihood; Welch t-test: Unpaired two-sample $t$ tests; IQR: Interquartile range; SD: Standard deviation; SMD: Standardised mean differences; X2: Chi-square tests; $\omega$ : McDonald's Omega; a: Cronbach's Alpha; Cl: Confidence intervals; $\rho$ : Spearman's rho; ICD-10: International Statistical Classification of Diseases and Related Health Problems, 10th revision; PTSD: Post-traumatic stress disorder; DASS-21: Depression, Anxiety and Stress Scales-21; R-GPTS: Revised-Green et al. Paranoid Thoughts Scale; WHO-5: WHO (Five) Well-Being Index
\end{abstract}

\section{Supplementary Information}

The online version contains supplementary material available at https://doi. org/10.1186/s12888-021-03425-6

\section{Additional file 1. Online Supplementary Material includes an}

overview of clinician's ascertained psychiatric diagnoses, item selection procedure, and final questionnaire version. Table S1 - Clinician's ascertained psychiatric diagnoses in the psychiatric inpatient sample based on ICD-10.

\section{Acknowledgments}

We are grateful to individuals participating in the NEAR-Survey and the LMU Biobank. We also thank Dr. Marcel Minke from Limesurvey-Consulting.com as well as Dr. Peter Zill, Sylvia de Jonge, and Dr. Sven Wichert from the LMU Psychiatric Hospital for their support in database set-up and data acquisition. We also thank Dr. Adela Isvoranu for helpful feedback on an earlier version of this manuscript.

\section{Authors' contributions}

$\mathrm{SR}, \mathrm{DF}, \mathrm{MR}, \mathrm{MB}$ and FP contributed to the study conception and design. Material preparation, data collection and analysis were performed by SR, MB and FP. The first draft of the manuscript was written by SR and all authors commented on previous versions of the manuscript. All authors read and approved the final manuscript.

\section{Funding}

This work was supported by the Network of Academic Medical Research into COVID-19 (Netzwerk Universitätsmedizin - NUM; grant number 01 KX2021), funded by the Federal Ministry of Education and Research (BMBF). Open Access funding enabled and organized by Projekt DEAL.

\section{Availability of data and materials}

The datasets used and/or analysed during the current study are available from the corresponding author on reasonable request.

\section{Declarations}

\section{Ethics approval and consent to participate}

The ethics committee of the Ludwig-Maximilians-University Munich approved the study (clinical sample [Project Number: 18-716]; non-clinical sample [Project Number: 20-118]) and the study was conducted in accordance with the Declaration of Helsinki (Association 2014). All participants provided informed consent prior to participation.

\section{Consent for publication}

Not applicable.

\section{Competing interests}

The authors have no competing interests as defined by BMC, or other interests that might be perceived to influence the results and/or discussion reported in this paper.

\section{Author details}

'Department of Psychiatry and Psychotherapy, LMU University Hospital Munich, Nussbaumstraße 7, Munich, Germany. ${ }^{2}$ International Max Planck Research School for Translational Psychiatry (IMPRS-TP), Munich, Germany. ${ }^{3}$ Department of Psychology, LMU Munich, Munich, Germany. ${ }^{4}$ Department of Psychiatry, University of Oxford, Oxford, UK.

Received: 9 April 2021 Accepted: 11 August 2021

Published online: 31 August 2021

References

1. Allington D, Duffy B, Wessely S, Dhavan N, Rubin J. Health-protective behaviour, social media usage and conspiracy belief during the COVID-19 public health emergency. Psychol Med. 2020;9:1-7. https://doi.org/10.1017/ S003329172000224X.

2. Freeman D, Waite F, Rosebrock L, Petit A, Causier C, East A, Jenner L, Teale AL, Carr L, Mulhall S, Bold E. Coronavirus conspiracy beliefs, mistrust, and compliance with government guidelines in England. Psychol Med. 2020;21: 1-3. https://doi.org/10.1017/S0033291720001890.

3. Gao J, Zheng P, Jia Y, Chen H, Mao Y, Chen S, et al. Mental health problems and social media exposure during COVID-19 outbreak. PLoS One. 2020;15(4): e0231924. https://doi.org/10.1371/journal.pone.0231924.

4. Rek SV, Freeman D, Reinhard M, Bühner M, Keeser D, Padberg F. The COVID19 Pandemic Mental Health Questionnaire (CoPaQ): introducing a comprehensive measure of the psychosocial impact of the current coronavirus crisis. Open Sci Framew. 2020.

5. Taquet, M, Luciano, S, Geddes, JR, Harrison, PJ. Bidirectional associations between COVID-19 and psychiatric disorder: retrospective cohort studies of 62354 COVID-19 cases in the USA. The Lancet Psychiatry. 2021;8(2):130-40. https://doi.org/10.1101/2020.08.14.20175190.

6. Wang, Q, Xu, R,Volkow, ND. Increased risk of COVID 19 infection and mortality in people with mental disorders: analysis from electronic health records in the United States. World Psychiatry. 2021;20(1):124-30. https://doi. org/10.1002/wps.20806.

7. Rubin GJ, Finn Y, Potts HWW, Michie S. Who is sceptical about emerging public health threats? Results from 39 national surveys in the United Kingdom. Public Health. 2015;129(12):1553-62 Available from: https://doi. org/10.1016/j.puhe.2015.09.004

8. Cori L, Bianchi F, Cadum E, Anthonj C. Risk perception and covid-19. Int J Environ Res Public Health. 2020;17(9):3114. https://doi.org/10.3390/ijerph1 7093114.

9. Harper CA, Satchell LP, Fido D, Latzman RD. Functional fear predicts public health compliance in the COVID-19 pandemic. Int J Ment Health Addiction. 2020;27:1-4. https://doi.org/10.1007/s1 1469-020-00281-5.

10. Wahl I, Kastlunger B, Kirchler E. Trust in authorities and power to enforce tax compliance: an empirical analysis of the "Slippery Slope Framework". Law Policy. 2010;32(4):383-406. https://doi.org/10.1111/j.1467-9930.2010.00327.x.

11. American Psychiatric Association. Diagnostic and statistical manual of mental disorders. United States; 2013. p. 21.

12. Cloitre M, Shevlin M, Brewin CR, Bisson Jl, Roberts NP, Maercker A, et al. The international trauma questionnaire: development of a self-report measure of ICD-11 PTSD and complex PTSD. Acta Psychiatr Scand. 2018;138(6):536-46. https://doi.org/10.1111/acps.12956.

13. Brooks SK, Webster RK, Smith LE, Woodland L, Wessely S, Greenberg N, et al. The psychological impact of quarantine and how to reduce it: rapid review of the evidence. Lancet. 2020;395(10227):912-20. https://doi.org/10.1016/ S0140-6736(20)30460-8.

14. Chong M-Y, Wang W-C, Hsieh W-C, Lee C-Y, Chiu N-M, Yeh W-C, et al. Psychological impact of severe acute respiratory syndrome on health workers in a tertiary hospital. Br J Psychiatry. 2004;185(2):127-33. https://doi. org/10.1192/bjp.185.2.127.

15. Qiu J, Shen B, Zhao M, Wang Z, Xie B, Xu Y. A nationwide survey of psychological distress among Chinese people in the COVID-19 epidemic: implications and policy recommendations. Gen Psychiatry. 2020;33(2):19-21.

16. Wang C, Pan R, Wan X, Tan Y, Xu L, Ho CS, et al. Immediate psychological responses and associated factors during the initial stage of the 2019 
coronavirus disease (COVID-19) epidemic among the general population in China. Int J Environ Res Public Health. 2020;17(5):1729. https://doi.org/10.33 90/ijerph17051729.

17. Stekhoven DJ, Bühlmann P. MissForest—non-parametric missing value imputation for mixed-type data. Bioinformatics. 2012;28(1):112-8. https://doi. org/10.1093/bioinformatics/btr597.

18. Yentes RD, Wilhelm F. careless: Procedures for computing indices of careless responding. R Packag version. 2018;1(3):2018.

19. Henry JD, Crawford JR. The short-form version of the Depression Anxiety Stress Scales (DASS-21): construct validity and normative data in a large non-clinical sample. Br J Clin Psychol. 2005;44(2):227-39. https://doi.org/1 0.1348/014466505X29657.

20. Nilges P, Essau C. Die Depressions-Angst-Stress-Skalen. Schmerz. 2015;29(6): 649-57. https://doi.org/10.1007/s00482-015-0019-z.

21. Antony MM, Cox BJ, Enns MW, Bieling PJ, Swinson RP. Psychometric properties of the 42-item and 21-item versions of the Depression Anxiety Stress Scales in clinical groups and a community sample. Psychol Assess. 1998;10(2):176-81. https://doi.org/10.1037/1040-3590.10.2.176.

22. Freeman D, Loe BS, Kingdon D, Startup H, Molodynski A, Rosebrock L, Brown P, Sheaves B, Waite F, Bird JC. The revised Green et al., Paranoid Thoughts Scale (R-GPTS): psychometric properties, severity ranges, and clinical cut-offs. Psych Med. 2021;51(2):244-53. https://doi.org/10.1017/ S0033291719003155.

23. Rek SV, Freeman D, Reinhard M, Bühner M, Padberg F. Psychometric evaluation of the German Revised-Green et al. Paranoid Thought Scales (RGPTS) across clinical and non-clinical samples. In preparation.

24. Organization WH. Wellbeing measures in primary health care/the DEPCARE project: report on a WHO meeting, Stockholm, Sweden 12-13 February 1998. In: Wellbeing measures in primary health care/the DEPCARE project: report on a WHO meeting, Stockholm, Sweden 12-13 February 1998; 1998.

25. Brähler E, Mühlan H, Albani C, Schmidt S. Teststatistische prüfung und normierung der deutschen versionen des EUROHIS-QOL lebensqualitätIndex und des WHO-5 wohlbefindens-index. Diagnostica. 2007;53(2):83-96. https://doi.org/10.1026/0012-1924.53.2.83.

26. Topp CW, Østergaard SD, Søndergaard S, Bech P. The WHO-5 Well-Being Index: a systematic review of the literature. Psychother Psychosom. 2015; 84(3):167-76. https://doi.org/10.1159/000376585.

27. Team RC. R: a language and environment for statistical computing; 2013.

28. Cohen J. Statistical power analysis for the behavioural sciences. Hillsdale: Laurence Erlbaum Associates. Inc; 1988.

29. Revelle W. psych: Procedures for psychological, psychometric, and personality research. R package version 2.1.6. Evanston: Northwestern University; 2021

30. Rosseel Y. Lavaan: an R package for structural equation modeling and more Version 0.5-12 (BETA). J Stat Softw. 2012;48(2):1-36.

31. Hu L, Bentler PM. Cutoff criteria for fit indexes in covariance structure analysis: conventional criteria versus new alternatives. Struct Equ Model Multidiscip J. 1999;6(1):1-55. https://doi.org/10.1080/10705519909540118.

32. Kelley K, Lai K, Lai MK, Suggests M. Package 'MBESS'; 2020.

33. Ho D, Imai K, Imai MK. Package 'Matchlt.' Version; 2018.

34. Sheskin DJ. Handbook of parametric and nonparametric statistical procedures. crc Press; 2004.

\section{Publisher's Note}

Springer Nature remains neutral with regard to jurisdictional claims in published maps and institutional affiliations.

Ready to submit your research? Choose BMC and benefit from:

- fast, convenient online submission

- thorough peer review by experienced researchers in your field

- rapid publication on acceptance

- support for research data, including large and complex data types

- gold Open Access which fosters wider collaboration and increased citations

- maximum visibility for your research: over $100 \mathrm{M}$ website views per year

At BMC, research is always in progress.

Learn more biomedcentral.com/submissions 